\title{
Poor consistency between reflux symptom index and laryngopharyngeal pH monitoring in laryngopharyngeal reflux diagnosis in Chinese population
}

\author{
Jun-Yao Wang, Tao Peng, Li-Li Zhao, Gui-Jian Feng, Yu-Lan Liu \\ Department of Gastroenterology, Peking University People's Hospital, Beijing, China \\ Contributions: (I) Conception and design: GJ Feng, YL Liu; (II) Administrative support: GJ Feng, YL Liu; (III) Provision of study materials or \\ patients: JY Wang, T Peng, GJ Feng; (IV) Collection and assembly of data: JY Wang, T Peng, LL Zhao; (V) Data analysis and interpretation: JY \\ Wang; (VI) Manuscript writing: All authors; (VII) Final approval of manuscript: All authors. \\ Correspondence to: Gui-Jian Feng. Department of Gastroenterology, Peking University People's Hospital, Beijing 100044, China. \\ Email: fggods@126.com; fengguijian@hsc.pku.edu.cn.
}

Background: It is unknown whether the reflux symptom index (RSI) can replace $\mathrm{pH}$ monitoring as a diagnostic tool for laryngopharyngeal reflux (LPR) in Chinese people. The relationships between reflux parameters and LPR symptoms also require further research.

Methods: A total of 216 Chinese patients underwent laryngopharyngeal $\mathrm{pH}$ monitoring and filled out an RSI questionnaire. Laryngopharyngeal $\mathrm{pH}$ monitoring indicated a diagnosis of LPR for patients with 7 or more episodes of reflux or a reflex area index (RAI) of 6.3 or more. The RSI questionnaire indicated a diagnosis of LPR for patients with RSI scores of 14 or higher.

Results: Of the 216 patients, 85 were diagnosed with LPR as assessed by the RSI, and 72 were diagnosed with LPR through laryngopharyngeal pH monitoring. The Cohen's kappa coefficient comparing LPR diagnosis consistency between RSI score and laryngopharyngeal $\mathrm{pH}$ monitoring was $0.133(\mathrm{P}=0.007)$. This indicated the two diagnostic methods were consistent to a low degree; the total consistency rate was only $59.7 \%$ (129/216). The sensitivity of the RSI was 48.6\% (35/72), and its specificity was 82.5\% (94/114). For convenience, we named the nine symptom groups in the RSI sequentially as P1-P9. P1, P2, P3, P5, P6, and $\mathrm{P} 7$ were all correlated with at least one reflux parameter $(\mathrm{P}<0.05)$, but $\mathrm{P} 4, \mathrm{P} 8$, and $\mathrm{P} 9$ were not correlated with any reflux parameters $(\mathrm{P}>0.05)$. A total of 72 patients were diagnosed using $\mathrm{pH}$ monitoring, the gold standard for LPR diagnosis. The most common symptoms of LPR were found to be P9, P3, P8, P7, and P2 in these patients. The symptoms that most seriously affected patients were P9, P8, P3, P7, and P2.

Conclusions: The consistency in diagnosis of LPR between the RSI and laryngopharyngeal $\mathrm{pH}$ monitoring was poor, meaning the RSI is not a suitable LPR initial screening tool and cannot replace $\mathrm{pH}$ monitoring. Additionally, reflux symptoms P4, P8, and P9 were not correlated with any reflux parameters. The most prevalent LPR symptom was P9, followed by P3, P8, P7, and P2. The most severe symptom was also P9, followed by P8, P3, P7, and P2.

Keywords: Laryngopharyngeal reflux (LPR); reflux symptom index (RSI); laryngopharyngeal pH monitoring; esophageal $\mathrm{pH}$ monitoring

Submitted Jun 22, 2020. Accepted for publication Oct 23, 2020.

doi: 10.21037/atm-20-4783

View this article at: http://dx.doi.org/10.21037/atm-20-4783 


\section{Introduction}

Laryngopharyngeal reflux (LPR) was first accepted by the American Academy of Otolaryngology in 2002 and is defined by the American Gastroenterology Association as a backflow of gastric contents into the laryngopharynx and upper aerodigestive tract (1). This condition is frequently complicated by other diseases, such as chronic pharyngitis, laryngitis, carcinoma, asthma, sleep apnea syndrome, et cetera, and may affect patient quality of life; under certain conditions, LPR can even be fatal $(2,3)$. Many gastroenterologists from different countries have reported a high prevalence of extraesophageal symptoms or LPR in patients with gastroesophageal reflux disease (GERD) $(4,5)$. Some posit that LPR is a complication of GERD, while others believe GERD is the primary cause of LPR (6).

LPR is diagnosed similarly to GERD. A principal method is symptom assessment. The reflux symptom index (RSI) (7) is the most commonly used type of symptom assessment, and its validity and reliability are accepted in many countries (8-11). Multiple studies have widely adopted the RSI questionnaire. Another method of LPR diagnosis is the reflux finding scoring (RFS) (12), in which laryngopharyngeal mucosa is examined by laryngoscopy to evaluate vocal cord edema, diffuse laryngeal edema, et cetera. However, RFS measures non-specific manifestations of LPR. For example, smoking or drinking can cause similar manifestations in patients. A recent study has found that RFS findings are not sufficiently indicative of LPR, even in GERD patients (13). Also, RFS focuses only on laryngeal signs, while LPR is a disease also characterized by hypertrophy of the lingual tonsils, hypo-erythema, or oropharyngeal erythema, and edema $(14,15)$. A third method to diagnose LPR is reflux evidence monitoring. There is general agreement, and many guidelines have indicated that reflux monitoring should be performed before patients receive experimental treatment (1). Wiener et al. have developed special instruments for oropharyngeal $\mathrm{pH}$ monitoring (16), and we performed preliminary exploration with these instruments in a previous study (17). Combined impedance-pH monitoring has more recently been used to diagnose LPR; however, this method does not yet have accepted normal reference value.

Reflux monitoring is an invasive examination; it takes at least 24 hours and is unpleasant for patients. More convenient diagnostic methods for both doctors and patients are therefore required. The RSI is relatively simple, but it is unknown whether it can replace $\mathrm{pH}$ monitoring as a tool to diagnose LPR in the Chinese population. The relationship between reflux parameters and LPR symptoms also requires further research.

We present the following article in accordance with the MDAR reporting checklist (available at http://dx.doi. org/10.21037/atm-20-4783).

\section{Methods}

This was a prospective study. The study was conducted in accordance with the Declaration of Helsinki (as revised in 2013). It was approved and supervised by the Ethics Committee of the Peking University People's Hospital [No. 2013 (28)] and informed consent was taken from all the patients.

\section{Patient recruitment}

Between August 2013 and January 2015, 216 eligible Chinese patients with at least one symptom of LPR voluntarily enrolled in this study and were evaluated at the Gastrointestinal Motility Lab of the Peking University People's Hospital. The inclusion criteria were as follows: (I) at least one symptom noted in the RSI or reflux disease questionnaire (RDQ); (II) 18-70 years old; and (III) no history of proton-pump inhibitor (PPI) or $\mathrm{H}_{2}$ receptor $\left(\mathrm{H}_{2} \mathrm{R}\right)$ medication in the previous month. The exclusion criteria were as follows: (I) unable to cooperate with instructions, such as patients with mental illness or a loss of consciousness; (II) cannot tolerate esophageal manometry or reflux monitoring, such as patients with an acute coronary syndrome, persistent asthma, acute cerebrovascular accident, etc.; and (III) endoscopy revealed a peptic ulcer, upper gastrointestinal tumor, or any other disease that would affect patient results.

\section{Symptom survey}

Under the guidance of professional personnel, participants filled out a general questionnaire, which included demographic characteristics and disaster-related data, as well as RSI questionnaires (see Figure 1) (7). The RSI questionnaire included nine groups of symptoms, and the severity of each symptom group was graded from 0 (no problem) to 5 (severe problem). When the total score was more than 13, a patient was considered as having LPR. The professional personnel checked the participants' questionnaires after completion to determine whether they 


\begin{tabular}{|c|c|c|c|c|c|c|}
\hline \multirow{2}{*}{$\begin{array}{l}\text { Within the last month, how did the following problems affect you? } \\
\text { Circle the appropriate response. }\end{array}$} & \multicolumn{6}{|c|}{$0=$ no problem } \\
\hline & \multicolumn{6}{|c|}{$5=$ severe problem } \\
\hline \multirow{9}{*}{$\begin{array}{l}\text { 1. Hoarseness or a problem with your voice } \\
\text { 2. Clearing your throat } \\
\text { 3. Excess throat mucus or postnasal drip } \\
\text { 4. Difficulty swallowing food, liquids, or pills } \\
\text { 5. Coughing after you ate or after lying down } \\
\text { 6. Breathing difficulties or choking episodes } \\
\text { 7. Troublesome or annoying cough } \\
\text { 8. Sensations of something sticking in your throat or a lump in your throat } \\
\text { 9. Heartburn, chest pain, indigestion, or stomach acid coming up }\end{array}$} & 0 & 1 & 2 & 3 & 4 & 5 \\
\hline & 0 & 1 & 2 & 3 & 4 & 5 \\
\hline & 0 & 1 & 2 & 3 & 4 & 5 \\
\hline & 0 & 1 & 2 & 3 & 4 & 5 \\
\hline & 0 & 1 & 2 & 3 & 4 & 5 \\
\hline & 0 & 1 & 2 & 3 & 4 & 5 \\
\hline & 0 & 1 & 2 & 3 & 4 & 5 \\
\hline & 0 & 1 & 2 & 3 & 4 & 5 \\
\hline & 0 & 1 & 2 & 3 & 4 & 5 \\
\hline & \multicolumn{5}{|c|}{ Total } & \\
\hline
\end{tabular}

Figure 1 the reflux symptom index. Reprinted from fournal of Voice, Vol 16, Issue 2, Belafsky PC, Postma GN, Koufman JA. Validity and reliability of the reflux symptom index (RSI), Copyright [2002], with permission from Elsevier.

qualified to participate in the study.

\section{Esophageal manometry}

We used equipment manufactured by Medical Measurement Systems (MMS) (Enschede, Netherlands) to perform esophageal manometry on each patient to confirm the position of the upper and lower esophageal sphincters (LES) and to exclude esophageal motility disorders. An electrical pump (Mui Scientific Mississauga, Ontario, Canada) and a six-channel (E6-1-1-5-5-5) esophageal water-perfused catheter were included in this process. After patients fasted for at least 8 hours, we inserted the catheter into the stomach through the nostril. Conventional esophageal manometry was performed with a pulling method and taking water swallows.

\section{Ambulatory 24-bour pH monitoring}

A Digitrapper MK III recorder (CTD-Synectics Medical, Sweden) and a dual-channel $\mathrm{pH}$ monitoring probe (Synectics Medical, Queluz, Portugal) were used. When esophageal manometry was complete, patients underwent ambulatory laryngopharyngeal and esophageal $\mathrm{pH}$ monitoring. Buffer solutions ( $\mathrm{pH} 7.0$ and $\mathrm{pH} 1.0$ ) were used to calibrate the electrode, which was then inserted into the esophagus through an unblocked nostril, the esophageal sensor being $5 \mathrm{~cm}$ above the superior margin of the LES, and the laryngopharyngeal sensor being 1-2 cm above the superior margin of the upper esophageal sphincter (UES). The patients recorded when they ate, drank, and lay in the supine position, as well as the occurrence of reflux symptoms. Monitoring ended after 24 hours. The collected data were analyzed by Polygram for Windows Release 2.04. Patients were diagnosed with LPR when they experienced 7 or more reflux events (a pH of less than 4 in the laryngopharynx), or the reflux area index (RAI) was 6.3 or more (18).

\section{Statistical analysis}

The required sample size was calculated using PASS 11 based on data from a previous study we conducted (19); the required sample size was at least 137 . We used IBM SPSS Statistics 22 to analyze the data. Normal distribution data were expressed as mean $\pm \mathrm{SD}$. The McNemar test and Cohen's kappa coefficient were used to test the consistency of LPR diagnosis between the RSI and $\mathrm{pH}$ monitoring. The Spearman test was used to determine the existence of correlations between reflux parameters and LPR symptoms. A chi-squared test was used to compare the proportions of patients with each symptom and a median test was used to compare symptom severity. A difference of $\mathrm{P}<0.05$ was considered statistically significant.

\section{Results}

A total of 216 eligible patients participated in this study between August 2013 and January 2015. Of these participants, 98 were male with an average age of $54 \pm 14$ years, and 118 were female with an average age of $54 \pm 12$ years. All patients underwent routine esophageal manometry, as well 
Table 1 RSI and laryngopharyngeal $\mathrm{pH}$ monitoring

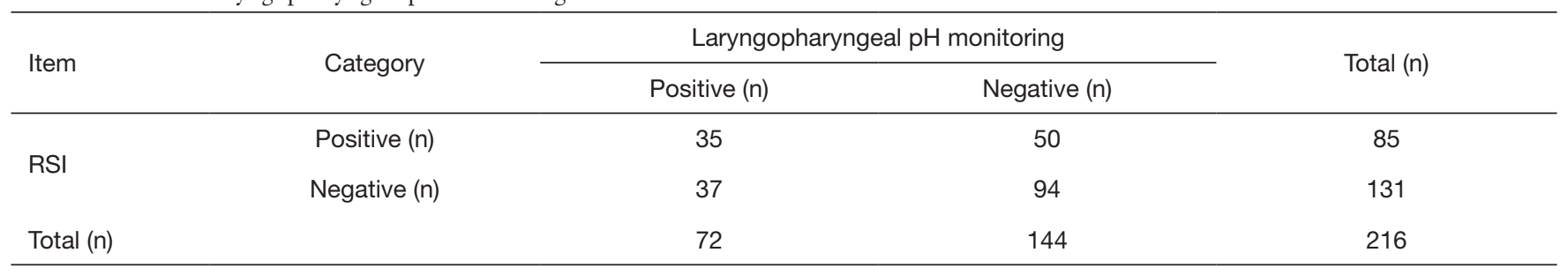

$\mathrm{RSI}$, reflux symptom index.

as laryngopharyngeal and distal esophageal $\mathrm{pH}$ monitoring. No severe adverse events were observed during our study. Therefore, no patients withdrew due to such adverse events as pharyngeal discomfort.

\section{Comparison of RSI and laryngopharyngeal pH monitoring in LPR diagnosis}

Of the 216 patients, according to RSI scores, 85 had LPR, and 131 did not have LPR. According to laryngopharyngeal pH monitoring, however, 72 had LPR, and 144 did not (see Table 1). LPR was diagnosed in 35 patients by both methods, 94 patients were excluded as having LPR by both methods, and the remaining 87 patients were diagnosed by one method and not the other. Compared with laryngopharyngeal $\mathrm{pH}$ monitoring, which is the golden standard for LPR diagnosis, RSI sensitivity was $48.6 \%$ (35/72), and its specificity was $82.5 \%$ (94/114). The total consistency rate was $59.7 \%$ (129/216), the positive predictive value was $41.2 \%(5 / 85)$, and the negative predictive value was $71.8 \%$ (94/131).

A McNemar test comparing the two methods produced a $\mathrm{P}$ value of 0.198 , which indicated that the difference between the results was not statistically significant. The kappa statistic, which compared the consistency of the two methods, produced a value of $0.133(\mathrm{P}=0.007)$, indicating the results were consistent only to a relatively low degree.

\section{Correlations between reflux parameters and LPR symptoms}

The RSI scale contains nine items (see Figure 1) (7): hoarseness or voice problems, throat clearing, excess throat mucus or postnasal drip, dysphagia, coughing after eating or lying down, dyspnea or choking episodes, troublesome or annoying cough, globus pharyngeus, and GERDrelated symptoms (heartburn, chest pain, indigestion, and stomach acid coming up). For the sake of convenience, we named these nine symptom groups sequentially as P1-P9. We chose the reflux parameters of upright reflux episodes, upright reflux time, percentage of upright reflux time, total reflux episodes, total reflux time, percentage of total reflux time, and RAI. We analyzed the correlations between these parameters and the nine reflux symptom groups. Details are included in Table 2, where $\mathrm{r}$ is the correlation coefficient, and $\mathrm{P}$ is the $\mathrm{P}$ value.

P1, P2, P3, P5, P6, and P7 were correlated with at least one reflux parameter $(\mathrm{P}>0.05)$. Coughing after eating or lying down, being P5, was correlated with all seven reflux parameters. A troublesome or annoying cough, P7, was correlated with six reflux parameters $(\mathrm{P}<0.05)$. However, P4, P8, and P9 were not correlated with any of the chosen reflux parameters $(\mathrm{P}>0.05)$.

\section{Symptom characteristics of LPR patients}

Of the 72 patients diagnosed with LPR by $\mathrm{pH}$ monitoring, 36 were male, and 36 were female with an average age of $54 \pm 14$ years.

Of these patients, 32 had symptom P1, 41 had symptom P2, 48 had symptom P3, 18 had symptom P4, 36 had symptom P5, 25 had symptom P6, 45 had symptom P7, 47 had symptom P8, and 57 had symptom P9. The proportion of patients with each symptom were $44.4 \%, 56.9 \%, 66.7 \%$, $25.0 \%, 50.0 \%, 34.7 \%, 62.5 \%, 65.3 \%$, and $79.2 \%$ from P1 to P9, respectively (see Figure 2). Figure 2 demonstrates the percentage of patients with symptoms among these 72 LPR patients diagnosed by $\mathrm{pH}$ monitoring. GERD-related symptoms, being P9, had the highest frequency (79.2\%), followed by P3, P8, and P7. Dysphagia, being P4, was the least prevalent symptom.

An independent samples median test (see Table 3), indicated a grand median score of 1 . The median scores of symptom severity on a scale of $0-5$ for $\mathrm{P} 1$ to $\mathrm{P} 9$ were 0,1 , 
Table 2 The correlation between reflux symptoms and reflux parameters in laryngopharynx

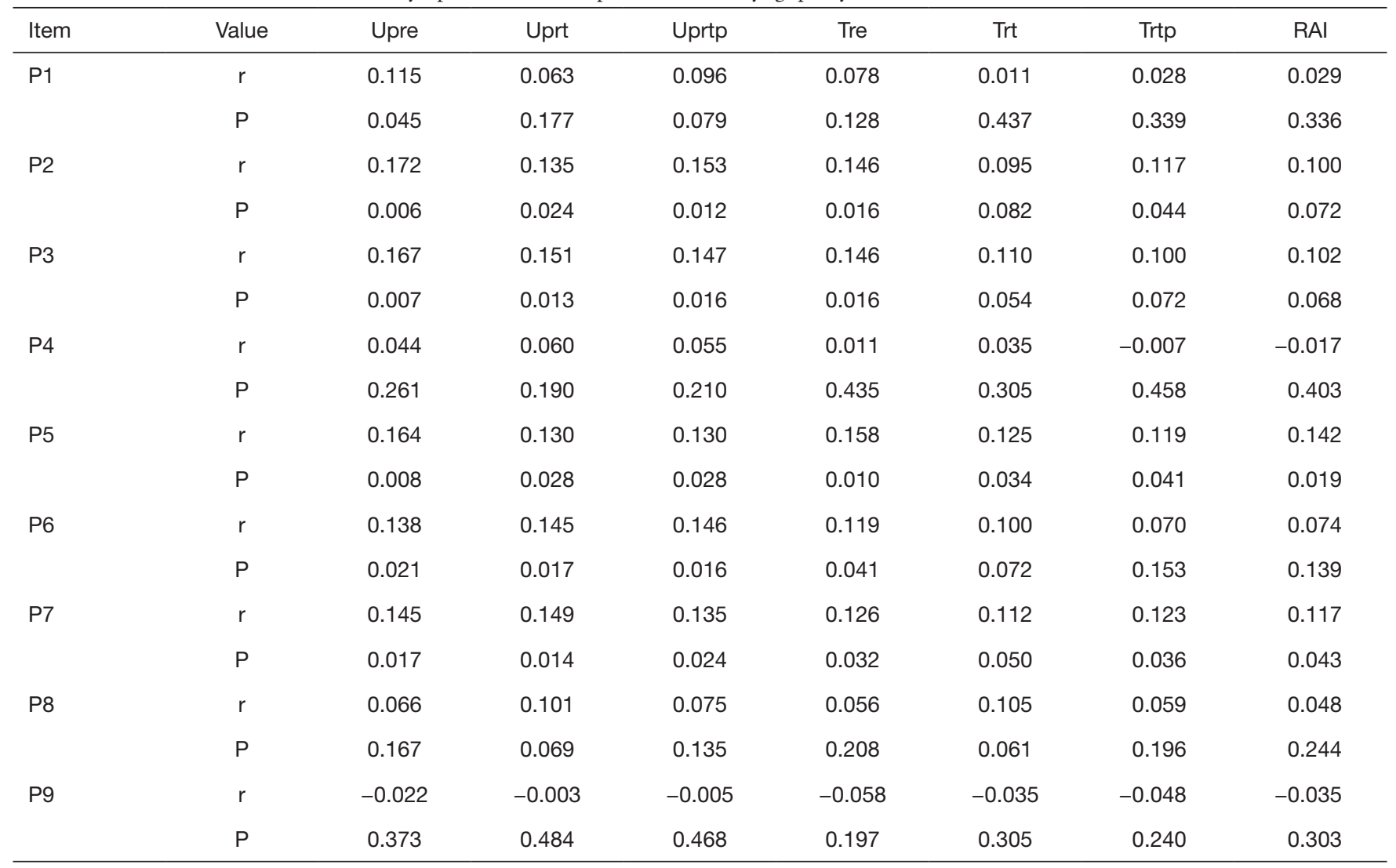

P1-P9, represents 9 groups of symptoms in the RSI scale; $r$, correlation coefficient; P, P value; Upre, upright reflux episodes; uprt, upright reflux time; uprtp, percentage of upright reflux time; tre, total reflux episodes; trt, total reflux time; trtp, percentage of upright reflux time; RAI, reflux area index.

Percentage of symptoms in patients with LPR (\%)

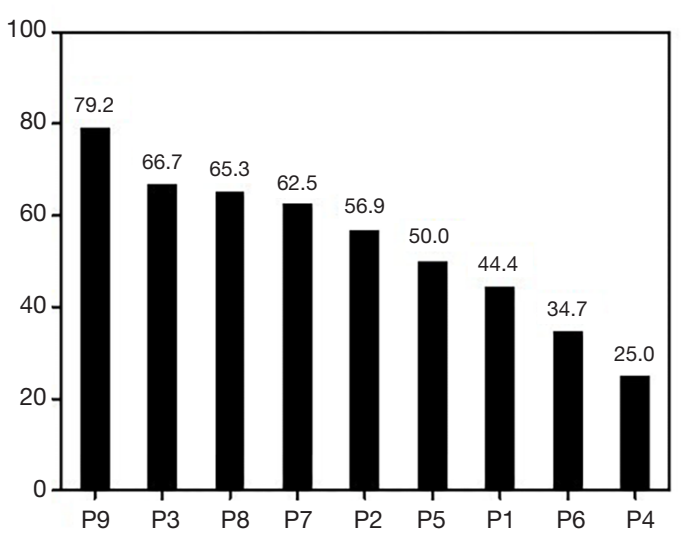

Figure 2 Percentage of symptoms in patients with LPR (\%). 72 patients was diagnosed with LPR by pH monitoring, and symptoms were analyzed according to the RSI questionnaire completed by each patient. The $\mathrm{X}$ axis is for different symptoms of the RSI scale, the $\mathrm{Y}$ axis is for the percentage of each symptom (\%). LPR, laryngopharyngeal reflux. 
Table 3 Homogeneous subsets based on severity

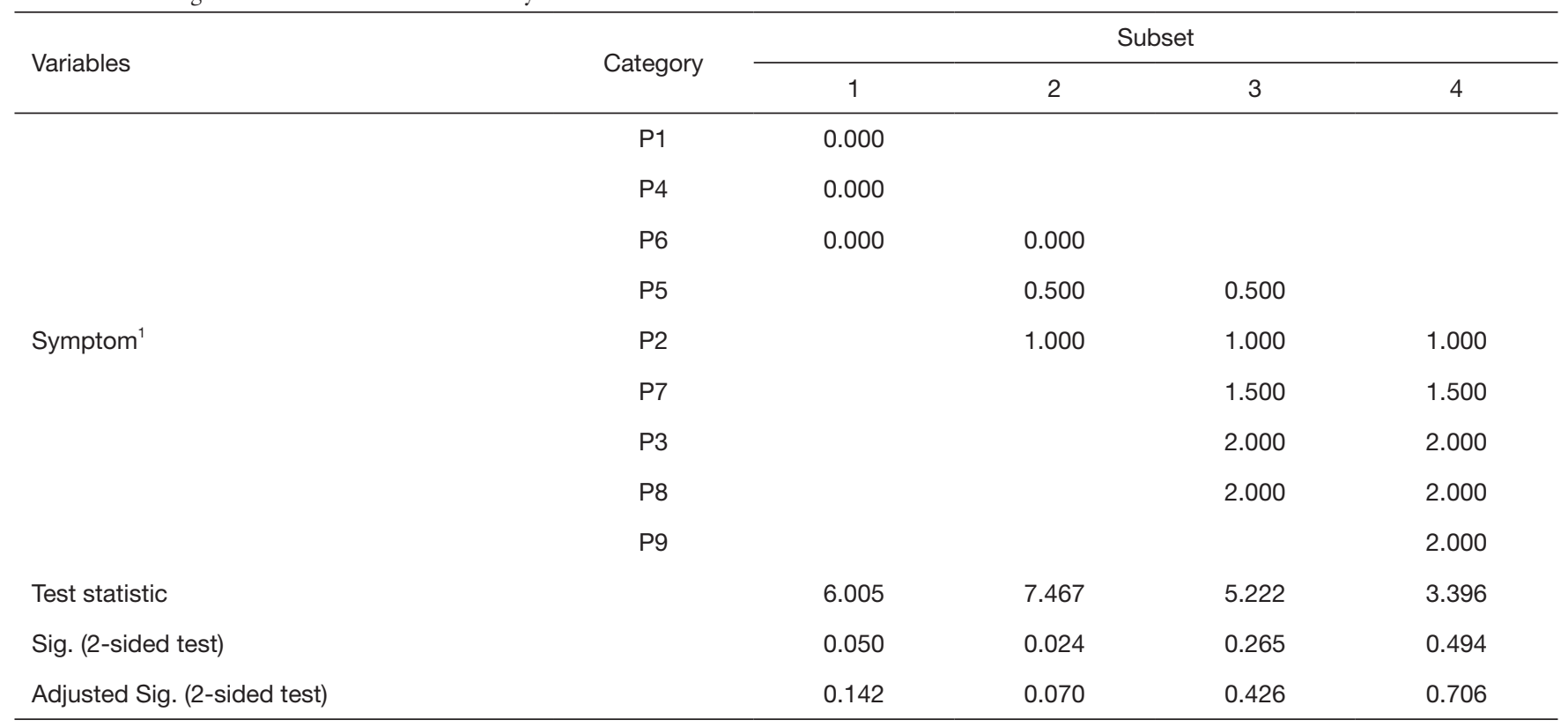

Homogeneous subsets are based on asymptotic significances. The significance level is $0.05 .{ }^{1}$, each cell shows the symptom median severity. P1-P9, represents 9 groups of symptoms in the RSI scale.

2, 0, 0.5, 0, 1.5, 2, and 2, respectively, and the difference was statistically significant (test statistic $=68.507, \mathrm{P}=0.000$ ). Based on an asymptotic significance of 0.05 , the symptoms were divided into four gradients. $\mathrm{P} 9, \mathrm{P} 8, \mathrm{P} 3, \mathrm{P} 7$, and $\mathrm{P} 2$ were in the highest gradient and affected patients most severely. P6, $\mathrm{P} 4$, and $\mathrm{P} 1$, however, were in the lowest gradient.

\section{Discussion}

The National Library of America includes LPR under GERD, meaning LPR is considered an example of the extraesophageal manifestations of GERD (20). A few years ago, we investigated the relationship between GERD and LPR based on symptoms and found they could coexist and manifest independently (6).

The RSI is a self-scoring index of symptom severity proposed and verified by Belafsky (7). Few studies, however, have focused on the relationship between RSI score and ambulatory laryngopharyngeal $\mathrm{pH}$ monitoring, or whether the RSI is suitable to diagnose LPR in Chinese patients. We conducted a study 10 years ago (19) and found the kappa value between the RSI and $\mathrm{pH}$ monitoring when used to diagnose LPR was $0.446(\mathrm{P}=0.007)$, despite the small sample size (31 participants). Several years ago, the validity and reliability of the Chinese version of the RSI were evaluated and believed to be of good validity and reliability (21). While this research was timely, the sample size was only 54 , and patients who underwent $\mathrm{pH}$ monitoring had positive RSI scores or RFSs for LPR, which affected the evaluation of the Chinese RSI diagnostic instrument.

A specific type of oropharyngeal monitoring is used to detect reflux in the oropharynx (16). In a previous study, we used the Dx-pH system to draw a normative database of the laryngopharynx $\mathrm{pH}$ profile in the Chinese population (22) and establish an animal model of LPR (17). However, this system is expensive and does not have an additional electrode to monitor the distal esophagus. As a result, in the current study, we used a dual $\mathrm{pH}$ probe catheter to detect reflux in the laryngopharynx and distal esophagus. The laryngopharynx $\mathrm{pH}$ electrode is generally placed 1-2 $\mathrm{cm}$ above the UES (18). To diagnose LPR, we applied the classical LPR diagnostic criteria: an RAI score of 6.3 or more, or 7 or more episodes of reflux (18).

Ambulatory laryngopharyngeal $\mathrm{pH}$-meter is considered a gold standard for the diagnosis of LPR. In the current study of 216 patients, compared with this gold standard, the RSI showed low sensitivity, a low consistency rate, a low positive predictive value, and a low negative predictive value. The kappa value was only 0.133 , meaning there was poor consistency between the two diagnostic methods. Given 
these results, the RSI is not a suitable substitute for $\mathrm{pH}$ monitoring in the Chinese population. However, as the RSI specificity was $82.5 \%$, it is a suitable LPR screening tool. Other gastroenterologists agree with our opinion on these matters $(23,24)$. Some researchers believe that age can affect the RSI diagnostic threshold for LPR (25), and another study using the Dx-pH system found that Ryan's scores, RSI, and RFS were poorly correlated with LPR detection (26).

Concerning reflux parameters and symptoms, while Duricek et al. (27) found no correlation between acidic pharyngeal reflux and symptoms of LPR, our results do not agree. In the current study, symptoms P1, P2, P3, $\mathrm{P} 5, \mathrm{P} 6$, and $\mathrm{P} 7$ were found to be correlated with at least one reflux parameter $(\mathrm{P}<0.05)$, though no correlation was found between any reflux parameter and $\mathrm{P} 4, \mathrm{P} 8$, or P9 $(\mathrm{P}>0.05)$. It is not strange that GERD-related symptoms, being $\mathrm{P} 9$, showed no correlation with reflux parameters, as the reflux parameters were measured at the laryngopharynx rather than the distal esophagus. Globus pharyngeus, being P8, referred to the sensation of having something stuck or a lump in the throat and was once considered a typical symptom of LPR. However, we found no correlation between $\mathrm{P} 8$ and any of the chosen reflux parameters; this is consistent with existing reports (28-31). We believe, rather, that globus pharyngeus is a symptom of lesions in the pharynx caused by chronic reflux, rather than an immediate reaction to reflux. The presence of globus pharyngeus without LPR may be due to high UES pressure (32). Dysphagia is this symptom referred to as $\mathrm{P} 4$. This symptom only occurred in $25 \%$ of LPR patients in our study, which is lower than that found in other research (33). The six remaining symptoms were all found to correlate with the reflux parameters investigated. P5 was correlated with all seven of the chosen reflux parameters, followed by P7, which was correlated with six. The primary symptom of both $\mathrm{P} 5$ and $\mathrm{P} 7$ is a cough, which is an immediate response to reflux. Yu et al. (34) reported that patients with GERDrelated chronic cough with higher RSI scores might have more proximal reflux. In summary, symptoms that occur as an immediate response to reflux appear to be related to reflux parameters, while those due to lesions caused by chronic reflux appear to be unrelated to reflux parameters.

Of the 72 patients diagnosed with LPR by $\mathrm{pH}$ monitoring in the current study, the most prevalent symptoms, in order, were $\mathrm{P} 9, \mathrm{P} 3, \mathrm{P} 8, \mathrm{P} 7$, and $\mathrm{P} 2$, and the most severe symptoms were $\mathrm{P} 9, \mathrm{P} 8, \mathrm{P} 3, \mathrm{P} 7$, and $\mathrm{P} 2$. P9, being GERD-related symptoms, are symptoms related to the digestive system, and the high prevalence of these symptoms accords with other research (5). Kamani et al. (35) reported that $75 \%$ of patients with LPR had symptoms of GERD. This indicates that LPR is closely related to GERD and that LPR is often secondary to this disease. Conversely to our study, however, other research found that globus pharyngeus $(\mathrm{P} 8)$, throat clearing $(\mathrm{P} 2)$, hoarseness $(\mathrm{P} 1)$, and excess throat mucus or postnasal drip (P4) were the most prevalent LPR symptoms (36). These differences may be due to patient differences or the method of LPR diagnosis.

One limitation of our study is that we did not adopt RFS to simultaneously evaluate patients, although the accuracy of RFS can be affected by multiple factors. Additionally, we did not adopt combined impedance $\mathrm{pH}$ monitoring. Combined impedance $\mathrm{pH}$ monitoring technology is at present rarely used to diagnose LPR and does not have an accepted normal laryngopharyngeal reference value. We intend to investigate this method of $\mathrm{pH}$ monitoring in the future.

In summary, the two methods of LPR diagnosis we investigated, the RSI and $\mathrm{pH}$ monitoring, do not produce consistent diagnoses. The RSI is therefore not a suitable replacement for reflux monitoring as an LPR diagnostic tool. However, RSI has a relatively high negative predictive value. For countries or regions with limited reflux monitoring conditions, RSI can be used to screen patients who benefit more from $\mathrm{pH}$ monitoring. Symptoms that are an immediate reaction to reflux were found to correlate with reflux parameters; further consideration of this may improve the diagnostic efficacy of the RSI. Finally, the most common and the most severe symptoms of LPR found were GERD-related symptoms, excess throat mucus or postnasal drip, globus pharyngeus, a troublesome or annoying cough, and throat clearing.

\section{Acknowledgments}

Funding: This study was supported by Capital Clinical Characteristics Application Research Project (grant number: Z131107002213069) due to the Beijing Municipal Science \& Technology Commission, China.

\section{Footnote}

Reporting Checklist: The authors have completed the MDAR reporting checklist. Available at http://dx.doi.org/10.21037/ atm-20-4783

Data Sharing Statement: Available at http://dx.doi. 
org/10.21037/atm-20-4783

Conflicts of Interest: All authors have completed the ICMJE uniform disclosure form (available at http://dx.doi. org/10.21037/atm-20-4783). The authors have no conflicts of interest to declare.

Etbical Statement: The authors are accountable for all aspects of the work in ensuring that questions related to the accuracy or integrity of any part of the work are appropriately investigated and resolved. The study was conducted in accordance with the Declaration of Helsinki (as revised in 2013). It was approved and supervised by the Ethics Committee of the Peking University People's Hospital [No. 2013 (28)] and informed consent was taken from all the patients.

Open Access Statement: This is an Open Access article distributed in accordance with the Creative Commons Attribution-NonCommercial-NoDerivs 4.0 International License (CC BY-NC-ND 4.0), which permits the noncommercial replication and distribution of the article with the strict proviso that no changes or edits are made and the original work is properly cited (including links to both the formal publication through the relevant DOI and the license). See: https://creativecommons.org/licenses/by-nc-nd/4.0/.

\section{References}

1. Katz PO, Gerson LB, Vela MF. Guidelines for the diagnosis and management of gastroesophageal reflux disease. Am J Gastroenterol 2013;108:308-28; quiz 329.

2. Parsel SM, Wu EL, Riley CA, et al. Gastroesophageal and Laryngopharyngeal Reflux Associated With Laryngeal Malignancy: A Systematic Review and Meta-analysis. Clin Gastroenterol Hepatol 2019;17:1253-1264.e5.

3. Lim KG, Morgenthaler TI, Katzka DA. Sleep and Nocturnal Gastroesophageal Reflux: An Update. Chest 2018;154:963-71.

4. Park S, Kwon JW, Park JM, et al. Treatment Pattern and Economic Burden of Refractory Gastroesophageal Reflux Disease Patients in Korea. J Neurogastroenterol Motil 2020;26:281-8.

5. Mosli M, Alkhathlan B, Abumohssin A, et al. Prevalence and clinical predictors of LPR among patients diagnosed with GERD according to the reflux symptom index questionnaire. Saudi J Gastroenterol 2018;24:236-41.

6. Feng GJ, Zhao LL, Zou N, et al. Symptom-based relationship between gastroesophageal reflux disease and laryngopharyngeal reflux disease. Zhonghua Yi Xue Za Zhi 2011;91:2472-5.

7. Belafsky PC, Postma GN, Koufman JA. Validity and reliability of the reflux symptom index (RSI). J Voice 2002;16:274-7.

8. Akbulut S, Aydinli FE, Kuş̧̧u O, et al. Reliability and Validity of the Turkish Reflux Symptom Index. J Voice 2020;34:965.e23-8.

9. Chen ZL, Wu HW, Mei XW, et al. Correlation analysis between $\mathrm{Dx}-\mathrm{pH}$ monitoring and proton pump inhibitor test in the diagnosis of laryngopharyngeal reflux disease. Zhonghua Er Bi Yan Hou Tou Jing Wai Ke Za Zhi 2020;55:34-9.

10. Schindler A, Mozzanica F, Ginocchio D, et al. Reliability and clinical validity of the Italian Reflux Symptom Index. J Voice 2010;24:354-8.

11. Lechien JR, Huet K, Finck C, et al. Validity and Reliability of a French Version of Reflux Symptom Index. J Voice 2017;31:512.e1-512.e7.

12. Dymek A, Dymek L, Starczewska-Dymek L, et al. Laryngopharyngeal Reflux (LPR) in patients with persistent hoarseness. Otolaryngol Pol 2012;66:33-8.

13. Vavricka SR, Storck CA, Wildi SM, et al. Limited diagnostic value of laryngopharyngeal lesions in patients with gastroesophageal reflux during routine upper gastrointestinal endoscopy. Am J Gastroenterol 2007;102:716-22.

14. Sung MW, Lee WH, Wee JH, et al. Factors associated with hypertrophy of the lingual tonsils in adults with sleepdisordered breathing. JAMA Otolaryngol Head Neck Surg 2013;139:598-603.

15. Harris MS, Rotenberg BW, Roth K, et al. Factors associated with lingual tonsil hypertrophy in Canadian adults. J Otolaryngol Head Neck Surg 2017;46:32.

16. Wiener GJ, Tsukashima R, Kelly C, et al. Oropharyngeal $\mathrm{pH}$ monitoring for the detection of liquid and aerosolized supraesophageal gastric reflux. J Voice 2009;23:498-504.

17. Feng G, Zhang Z, Diao C, et al. A bama minipig model of laryngopharyngeal reflux and the change of laryngopharyngeal mucosal ultrastructure. J Neurogastroenterol Motil 2015;21:182-8.

18. Vincent DA Jr, Garrett JD, Radionoff SL, et al. The proximal probe in esophageal $\mathrm{pH}$ monitoring: development of a normative database. J Voice 2000;14:247-54.

19. Feng GJ, Zhang LH, Zhao LL, et al. A pilot study on diagnosing laryngopharyngeal reflux disease by $\mathrm{pH}$ monitoring in laryngopharynx. Zhonghua Yi Xue Za Zhi 
2008;88:805-8.

20. Plocek A, Gębora-Kowalska B, Białek J, et al. Esophageal Impedance-pH Monitoring and Pharyngeal $\mathrm{pH}$ Monitoring in the Diagnosis of Extraesophageal Reflux in Children. Gastroenterol Res Pract 2019;2019:6271910.

21. Zheng JY, Zhang LH, Li JJ, et al. Chinese version of the reflux symptom index was evaluated for reliability and validity. Zhonghua Er Bi Yan Hou Tou Jing Wai Ke Za Zhi 2012;47:894-8.

22. Feng G, Wang J, Zhang L, et al. A Study to Draw a Normative Database of Laryngopharynx pH Profile in Chinese. J Neurogastroenterol Motil 2014;20:347-51.

23. Włodarczyk E, Miaśkiewicz B, Raj-Koziak D, et al. The application of 24-hour pharyngeal pH-monitoring and Reflux Finding Score and Reflux Symptom Index questionnaires in the diagnostics of laryngopharyngeal reflux. Prz Gastroenterol 2019;14:274-82.

24. Maldhure S, Chandrasekharan R, Dutta AK, et al. Role of PH Monitoring in Laryngopharyngeal Reflux Patients with Voice Disorders. Iran J Otorhinolaryngol 2016;28:377-83.

25. Qi Z, Zhang Y, Su R, et al. The influence of age on the score of reflux symptom index scale and reflux finding score scale in the diagnosis of pharyngeal and laryngeal reflux. Lin Chung Er Bi Yan Hou Tou Jing Wai Ke Za Zhi 2020;34:170-2.

26. Wang G, Qu C, Wang L, et al. Utility of 24-hour pharyngeal $\mathrm{pH}$ monitoring and clinical feature in laryngopharyngeal reflux disease. Acta Otolaryngol 2019;139:299-303.

27. Duricek M, Banovcin P, Halickova T, et al. Acidic Pharyngeal Reflux Does Not Correlate with Symptoms and Laryngeal Injury Attributed to Laryngopharyngeal Reflux. Dig Dis Sci 2019;64:1270-80.

Cite this article as: Wang JY, Peng T, Zhao LL, Feng GJ, Liu YL. Poor consistency between reflux symptom index and laryngopharyngeal $\mathrm{pH}$ monitoring in laryngopharyngeal reflux diagnosis in Chinese population. Ann Transl Med 2021;9(1):25. doi: $10.21037 /$ atm-20-4783
28. Kim SI, Kwon OE, Na SY, et al. Association between 24hour combined multichannel intraluminal impedance$\mathrm{pH}$ monitoring and symptoms or quality of life in patients with laryngopharyngeal reflux. Clin Otolaryngol 2017;42:584-91.

29. Penović S, Roje Ž, Brdar D, et al. Globus Pharyngeus: A Symptom of Increased Thyroid or Laryngopharyngeal Reflux. Acta Clin Croat 2018;57:110-5.

30. Ott DJ, Ledbetter MS, Koufman JA, et al. Globus pharyngeus: radiographic evaluation and 24-hour $\mathrm{pH}$ monitoring of the pharynx and esophagus in 22 patients. Radiology 1994;191:95-7.

31. Chen CL, Tsai CC, Chou AS, et al. Utility of ambulatory $\mathrm{pH}$ monitoring and videofluoroscopy for the evaluation of patients with globus pharyngeus. Dysphagia 2007;22:16-9.

32. Ding H, Duan Z, Yang D, et al. High-resolution manometry in patients with and without globus pharyngeus and/or symptoms of laryngopharyngeal reflux. BMC Gastroenterol 2017;17:109.

33. Pisegna JM, Yang S, Purcell A, et al. A Mixed-Methods Study of Patient Views on Reflux Symptoms and Medication Routines. J Voice 2017;31:381.e15-381.e25.

34. Yu Y, Wen S, Wang S, et al. Reflux characteristics in patients with gastroesophageal reflux-related chronic cough complicated by laryngopharyngeal reflux. Ann Transl Med 2019;7:529.

35. Kamani T, Penney S, Mitra I, et al. The prevalence of laryngopharyngeal reflux in the English population. Eur Arch Otorhinolaryngol 2012;269:2219-25.

36. Lechien JR, Saussez S, Karkos PD. Laryngopharyngeal reflux disease: clinical presentation, diagnosis and therapeutic challenges in 2018. Curr Opin Otolaryngol Head Neck Surg 2018;26:392-402. 